\title{
Contratos no Mercado de Trabalho Agrícola: o Caso das Cooperativas de Trabalhadores Rurais ${ }^{1}$
}

Jefferson A. R. Staduto², Weimar F. Rocha Jr³, Mayra B. Bitencourt ${ }^{4}$

Resumo: O objetivo central deste estudo é analisar os sistemas de contratação do trabalhador temporário na agricultura brasileira, e, principalmente, por meio das cooperativas de trabalhadores rurais, e considerando a ótica das instituições jurídicas. O estudo foi abordado a partir da abordagem da Nova Economia Institucional. As instituições jurídicas são importantes componentes na formatação do sistema de contratação; a atuação dessas instituições tende a restringir algumas formas de contratação e incentivar outras. Verificou-se que as instituições jurídicas apresentavam grandes restrições quanto ao funcionamento e contratação das cooperativas de trabalhadores rurais, pois muitas delas apresentavam um caráter fraudulento, acarretando perda de diretos trabalhistas à mão-de-obra que prestava serviço nas propriedades rurais por

\footnotetext{
${ }^{1}$ Agradecemos os comentários e as sugestões dos pareceristas anônimos bem como a colaboração da bacharel em direito Lizete Deimling.

${ }^{2}$ Doutor em Economia Aplicada e professor do Curso de Ciências Econômicas e do Mestrado em Desenvolvimento Regional e Agronegócio da UNIOESTE/Toledo e membro do Grupo de Pesquisa em Agronegócio e Desenvolvimento Regional (GEPEC) - staduto@unioeste

${ }^{3}$ Doutor em Engenharia da Produção e professor do Curso de Ciências Econômica e do Mestrado em Desenvolvimento Regional e Agronegócio da UNIOESTE/Toledo e membro do Grupo de Pesquisa em Agronegócio e Desenvolvimento Regional (GEPEC) -wrocha@unioeste.br

${ }^{4}$ Doutora em Economia Aplicada e professora do Curso de Direito e do Mestrado em Economia de Empresas e Agronegócio da FEAD-MINAS/BH - mayra_bitencourt@yahoo.com.br
} 
meio das cooperativas. Além disso, as empresas que contratavam essas cooperativas estariam gerando elevados riscos potenciais de custos de transação adotando este sistema de contração de trabalhadores rurais.

Palavras-chave: contrato de trabalho, cooperativa de trabalhadores rurais, instituições jurídicas.

\section{Classificação JEL: K31}

Abstract: The purpose of this study is to analyze the agricultural seasonal labor contract system and mainly the rural labor cooperatives, from the legal system's point of view. Legal institutions are important components that affect the agricultural seasonal labor contract. Therefore, these institutions trend to restrict some contract frameworks and to provide incentive to other contracts. The work verified that rural labor cooperatives have high restrictions from legal institutions. The reason is the high incidence of corruption in this contract system. Thus, there is a potential increase in the transactions cost of the labor contract system.

Key words: labor contract, rural labor cooperative, institutions judicial.

\section{JEL Classification: K31}

\section{Introdução}

O objetivo central deste trabalho é analisar o sistema de contratação da mão-de-obra temporária agrícola, mais especificamente os serviços prestados pelas cooperativas de trabalhadores rurais, sobretudo sob a ótica das instituições jurídicas. Essas instituições são um dos componentes importantes que moldam o sistema de contratação da mão-de-obra, tendo um grande potencial de restringir algumas formatações contratuais e de incentivar outras. Com a finalidade de analisar os contratos, foi realizada uma breve discussão acerca da abordagem teórica na ótica contratual do mercado de trabalho.

A contratação do trabalho assalariado temporário é parte da rotina do processo produtivo das atividades agropecuárias, por mais que pese a intensa substituição do trabalho obreiro por máquinas e equipamentos, 
com a finalidade de automatizar as várias etapas das atividades agrícolas. A mão-de-obra volante pode ser vista como uma situação transitória na forma de produção capitalista. A transição requer tempo e tecnologia disponíveis para substituir o trabalho obreiro. A substituição do trabalho temporário também requer investimento em capital, ou seja, há custos na aquisição das tecnologias poupadoras de mão-de-obra disponível para o setor agropecuário. A transição do trabalho obreiro para o automatizado é um processo lento nas etapas mais adiantadas e provavelmente será permanentemente incompleta. Com efeito, esse processo de substituição de fatores de produção enfrenta limites temporais e financeiros.

As profundas transformações que transcorreram no setor agropecuário, principalmente nas últimas três décadas, modificaram a forma de produzir e a organização da produção, propiciando condições para o surgimento do fenômeno do trabalhador temporário (bóia-fria ou volante). Entre os fatores que contribuíram para o surgimento dos trabalhadores temporários destacam-se dois movimentos que ocorreram simultaneamente: o processo de modernização do setor agropecuário e a implementação de legislações que ampliavam os direitos dos trabalhares rurais - Estatutos da Terra (alguns preceitos desse Estatuto foram contemplados na Constituição de 1988) e do Trabalhador Rural.

A força de trabalho agrícola temporária é, basicamente, formada por mão-de-obra não-qualificada, o que implica um reduzido poder de barganha na negociação salarial e, além disso, incentiva o não-cumprimento dos direitos trabalhistas. Embora as firmas contratantes tenham à disposição uma situação favorável no recrutamento desses indivíduos, nas regiões mais desenvolvidas encontram restrições imputadas pelas instituições jurídicas - Delegacia do Trabalho, Justiça do Trabalho e Ministério Público do Trabalho. A presença desse aparato institucional está, em certa medida, restringindo algumas práticas de contratações, como é o caso das cooperativas de trabalhadores rurais, e induzindo outras formas de contratação.

A cooperativa de trabalho é um meio pelo qual os trabalhadores rurais se organizam e gerenciam suas forças com maior poder de barganha no mercado, para alcançar melhores condições de trabalho, particularmente em situações em que eles se encontram desprovidos total ou parcialmente de direitos trabalhistas. Como trabalhadores autônomos, por meio 
da assistência social da cooperativa, os associados podem assegurar direitos trabalhistas alcançados às suas necessidades prioritárias. Dessa forma, as cooperativas de trabalhadores rurais, por suas características, tendem a amenizar os conflitos entre as partes. Os empregadores têm a possibilidade de reduzir os custos de transação, além de facilitar o recrutamento da mão-de-obra; e os empregados podem com maior facilidade assegurar seus direitos e remunerações. Entretanto, para que a organização cooperativa funcione em condições de atender ao que se propõe, é necessário o desenvolvimento de um processo de comunicação e de educação cooperativista em consonância com os princípios e valores do cooperativismo, para uma efetiva participação dos associados na gerência do empreendimento.

A abordagem contratual do mercado de trabalho apresenta uma vertente desenvolvida pela teoria dos contratos pelos autores da Nova Economia Institucional, e outras vertentes pelas teorias com fundamentos keynesianos. As duas abordagens comportam a ótica institucional, entretanto este trabalho explorou com mais detalhes as formulações da Nova Economia Institucional.

Para alcançar os objetivos propostos, organizou-se este trabalho em seis seções, incluindo esta introdução. Na segunda seção são apresentadas as abordagens relativas ao surgimento do trabalhador temporário na agropecuária brasileira. Na terceira seção é conduzida uma discussão teórica sobre os contratos e o ambiente institucional do mercado de trabalho agrícola. Na quarta seção são apresentados os principais contratos de trabalho agrícola praticados no setor agropecuário. Na quinta parte são analisadas as cooperativas de trabalhadores rurais. E, finalmente, na última seção constam as considerações finais.

\section{O Fenômeno do bóia-fria}

Apesar da redução de importância do setor agropecuário na composição da renda nacional nas últimas décadas, a população economicamente ativa (PEA) rural ainda responde por cerca de $24 \%$ do total da PEA nacional (IBGE, 1999). Trata-se de um setor que absorve número expressivo de trabalhadores não-qualificados na economia nacional. Os trabalhadores com carteira assinada correspondem a apenas $29 \%$ do 
emprego total na agricultura, o que mostra o alto grau de informalidade nesse setor (AMADEU, 1999).

De acordo com Cacciamali (2001), essa informalidade induziu mudanças institucionais nas relações de trabalho. Reformas laborais foram promulgadas introduzindo contratos alternativos ao contrato de trabalho permanente, diminuindo custos e direitos sociais.

Na agropecuária brasileira cristalizaram-se vários esquemas de relações de trabalho. Segundo Goodman et al. (1985), os meeiros, os arrendatários ou os trabalhadores residentes são trabalhadores assalariados disfarçados. A proletarização desses indivíduos ocorreu a partir dos anos 60 com o processo de capitalização do setor agropecuário, ou seja, com a modernização da agricultura.

Cacciamali (1986) sintetizou em dois grupos as discussões no meio acadêmico sobre as razões que provocaram o crescimento em algumas regiões ou, até mesmo, o surgimento da utilização da mão-de-obra temporária nas atividades agropecuárias. Até a década de 60, este segmento de trabalhadores era praticamente inexistente. O primeiro grupo é formado pelos autores que associam o crescimento da utilização da mão-de-obra temporária com o surgimento dos Estatutos da Terra e do Trabalhador Rural e seus desdobramentos (ETR, Lei 4.214 de 1963). Esses autores argumentam que os empregadores rurais, para se eximirem do pagamento dos direitos regulados pelo ETR, expulsaram ou reduziram ao máximo os trabalhadores agrícolas residentes em suas fazendas. Os fazendeiros acreditavam que os custos e as obrigações imputadas pela legislação eram muito elevados, considerando a baixa qualidade da força de trabalho empregada e a descontinuidade inerente ao processo produtivo nas atividades agropecuárias.

Portanto, sob esta ótica, após 1963, a necessidade de trabalho temporário nas atividades agropecuárias e a reorganização das relações de trabalho se traduziriam em ônus para os empregadores. A forma de burlar a legislação vigente foi a descaracterização dos vínculos empregatícios e do assalariamento, por meio da utilização do trabalho intermitente (trabalho ilegal ou clandestino).

O outro grupo de pesquisadores atribuiu o crescimento do trabalho assalariado temporário na agropecuária, após os anos 60, a uma nova fase do desenvolvimento capitalista do país e do próprio setor agrope- 
cuário. Esses pesquisadores não acreditam que a aplicação da legislação - os Estatutos da Terra e do Trabalhador Rural - seja o fator causador do fenômeno "trabalhador temporário". A persistência e o crescimento dessa modalidade de relação de trabalho estariam ligados à especialização numa mesma atividade agrícola, o que implicaria a intensificação do uso do trabalho temporário. Esse fato ocorreu independentemente da incidência, ou não, de encargos trabalhistas sobre os salários pagos aos trabalhadores agrícolas. Cacciamali (1986) reforça esses argumentos, pois na sua opinião não é correta a afirmação de que o surgimento de legislação específica, regulamentando as relações de trabalho no campo, seja responsável pelo aparecimento do assalariamento temporário.

Cacciamali (1986) e Brant (1977) têm a mesma opinião de Mello (1975, p. 147): o bóia-fria é a afirmação "histórica do sistema”. Conforme Mello (1975), o bóia-fria, componente das fileiras dos ofertantes de força de trabalho e membro da superpopulação relativa, é, com efeito, a afirmação do sistema capitalista. "A forma que esse indivíduo realiza o seu trabalho no campo é uma decorrência da existência deste excedente da oferta de força de trabalho, em relação à demanda. A possibilidade de contar com um tipo de trabalho que, recebendo por tarefa ou por dia, trabalhando num ritmo irregular favorece os interesses do empregador, existe, em última análise, como decorrência da superabundância de mão-de-obra” (MELLO, 1975, p. 87).

Aguirre e Bianchi (1989) formularam uma interpretação diferenciada da questão do surgimento do trabalhador temporário. As autoras analisaram esse fenômeno a partir da constatação da necessidade de acumulação para a atividade capitalista. No caso brasileiro poderia haver, à primeira vista, três possíveis opções para acumulação de capital: extensão da jornada de trabalho, aumento da intensidade do trabalho e aumento de sua produtividade. A primeira opção não parecia uma alternativa factível, pois a jornada de trabalho já era suficientemente exaustiva. No caso do aumento da intensidade do trabalho, só seria viável se houvesse um forte incentivo para o trabalhador. No entanto, quando se trata de trabalho manual, há dificuldades de controle rigoroso sobre o esforço despendido. A terceira opção, o aumento da produtividade do trabalho, viabiliza-se por meio de investimento em capital fixo.

Segundo Aguirre e Bianchi (1989), a mobilização de capital para o 
setor sofria restrições, portanto, em condições de ampla disponibilidade de mão-de-obra, a alternativa para capitalização da agropecuária poderia ser a utilização do trabalho temporário. Dessa forma, esse tipo de trabalho seria útil no processo de transição de uma agricultura tradicional para uma agricultura tecnicamente mais adiantada. Como nos últimos dez anos o processo de tecnificação do setor agropecuário intensificou-se, houve uma redução na relação entre trabalho e capital.

O fenômeno do surgimento do trabalhador temporário apresenta várias versões, no entanto a argumentação de Aguirre e Bianchi (1989) demonstra que se trata de uma situação transitória. Segundo a interpretação desses autores, a relação entre trabalhadores temporários e volantes tenderia a aumentar inicialmente e, com o desenvolvimento do capitalismo (aumento do capital), da agricultura, reduziria, configurando, dessa forma, o papel de transição desse tipo de trabalhador. Essa transição é lenta e, provavelmente, deva ter uma zona de fronteira para extinção desse tipo de ocupação de difícil transposição, no qual a tecnologia poupadora de mão-de-obra tenha que ter a relação entre custo e benefício favorável, de tal forma que uma determinada firma (empresa rural) adote tecnologias poupadoras de mão-de-obra.

Nota-se, com o trabalho de Vandeman et al. (1991), que mesmo nas economias com a agricultura mais desenvolvida, como é caso do estado americano da Califórnia, os contratos de trabalho são uma antiga instituição do setor agrícola. Esses autores citam que os agentes que fazem a intermediação do trabalho agrícola estão presentes na agricultura da Califórnia há mais de 100 anos. A tarefa obreira está presente mesmo na agricultura mais tecnificada, pois a substituição das tarefas realizadas pela mão-de-obra não-qualificada por máquinas e equipamentos não é disseminada e factível de forma generalizada.

\section{Abordagem teórica das relações contratuais do mercado de trabalho}

Os contratos de trabalho (formais e informais) não são, normalmente, objeto de análise, apesar de serem instrumentos fundamentais na coordenação do processo produtivo. Essa situação nos remete a uma nova investigação dos autores que contribuíram para elucidar como os 
contratos são firmados, bem como o ambiente institucional que rege as relações dos agentes imersos nesses contratos.

Nas abordagens teóricas keynesianas e da Nova Economia Institucional, os contratos de trabalho emergem como instrumentos fundamentais nos estudos do trabalho, os quais geram implicações fundamentais nesse mercado. Para a tarefa de explicitar as contribuições da teoria keynesina e, naturalmente, da Nova Economia Institucional, esta seção está dividida em duas partes. Na primeira é realizada uma reflexão sobre a contribuição de Keynes e os desdobramentos de sua teoria, e, principalmente, dos modelos mais recentes - os novos keynesianos. Na segunda parte, analisa-se a contribuição dos autores da Nova Economia Institucional.

\subsection{A Teoria dos Contratos}

Keynes introduz o contrato de trabalho em sua Teoria Geral, tendo a proposição funcional de restringir a rápida flutuação dos salários e dos indivíduos empregados. Dessa forma, as firmas não podem dispensar os trabalhadores para ajustar oferta e demanda.

Este grupo de autores, os novos keynesianos, a princípio, tinha o papel teórico de alicerçar microanaliticamente a rigidez salarial ${ }^{5}$, tanto que eles formularam modelos que trazem à tona vários aspectos e conceitos importantes nas relações do trabalho. Esses modelos suscitam vários tipos de ajustamento para justificar a rigidez salarial, tais como custo de rotatividade da mão-de-obra e da seleção adversa de novos trabalhadores. Froyen (1999) denomina essa abordagem como sendo contratual.

Nas relações contratuais estão explícitas as cláusulas jurídicas, sociais e econômicas. Há razões que motivariam os trabalhadores a cumprir os seus contratos de trabalho mesmo que os julgassem injustos; por exemplo, a jornada de trabalho e a remuneração das atividades que exercem. Segundo Amadeo (1992), os trabalhadores não abandonam o contrato pelas seguintes razões: a) quando há perdas salariais, é mais provável que os trabalhadores demandem revisão salarial; b) o trabalho cumpre um papel social e cultural

\footnotetext{
${ }^{5}$ Rigidez salarial é um aspecto fundamental da teoria de Keynes, segundo a qual os salários nominais não têm grandes flutuações em razão de os contratos serem explicita ou implicitamente firmados.
} 
importante para o trabalhador; e c) caso não haja benefícios adequados para o desempregado, essa situação pode ter conseqüências desastrosas para a família do trabalhador. No segmento do mercado de trabalho onde não há contrato explícito que fixa o salário monetário, costuma haver acordos implícitos que fixam os salários durante um período, bem como muitas das regras das relações do trabalho, tais como jornada de trabalho, finais de semana remunerados, horário para as refeições e outros.

Dentro dos custos de rotatividade da mão-de-obra que são imputados à firma, vários são considerados fatores institucionais, os quais delimitam o livre ajustamento dos mercados de trabalho. Os novos keynesianos incorporam nos modelos microeconômicos os custos de rotação da mão-de-obra, que pressupõem custos de treinamento, de recrutamento, de dispensa, de perda de produtividade, e outros relacionados ao fator humano. O contratante (firma) assume papel predominante no mercado de trabalho, entretanto tem grandes restrições para não dispensar os trabalhadores empregados e para admitir os trabalhadores desempregados com salários menores.

O processo de contratação e dispensa da mão-de-obra gera custos de transação e custos de produção para a firma. Os custos de transação podem ser definidos em quatro níveis: o primeiro nível relaciona-se com os custos de construção e negociação dos contratos; o segundo envolve os custos em medir e monitorar os direitos de propriedade existentes no contrato. Nesse nível incorporam-se os custos de observação dos contratos ao longo do tempo para monitorar seu desempenho e atende-se às expectativas das partes que fizeram a transação. O terceiro nível engloba os custos de manter e fazer executar os contratos internos e externos da firma. O quarto e último nível relaciona-se com os custos de adaptação que os agentes sofrem com as mudanças ambientais (FARINA, 1999). Nesse sentido, o custo de transação é composto de vários níveis, desde os agentes econômicos do recrutamento até os custos institucionais de ordem trabalhista.

Os custos de produção são devidos à queda na produtividade devido à falta de perícia na rotina do trabalho dos novos trabalhadores e à falta de aplicação no processo produtivo em razão dos baixos salários. O processo de treinamento da mão-de-obra pode ser abordado como investimento em capital humano. Segundo Oi (1962 apud FREITAS, 1992), o treinamento que a mão-de-obra recebe na firma impede que o 
trabalho seja tratado como fator de produção variável. Dessa forma, Oi (1962) classifica-o como um insumo quase fixo.

Williamson (1985) reforça essa idéia de investimento em capital humano por meio da abordagem da especificidade do trabalho, tendo o seguinte mecanismo de ajustamento: quanto maior a especificidade do trabalho, maior será o investimento em treinamento e maior será o interesse da firma de manter um quadro estável de empregados.

Em termos de abordagens teóricas que consideram custos dessa natureza, há os modelos "novos keynesianos”. A aplicação empírica desses modelos é realizada por vários autores, principalmente nos estudos sobre o mercado de trabalho urbano; no entanto, constatam-se poucas publicações para o mercado de trabalho agrícola. Nota-se que, tratando-se de mão-de-obra pouco qualificada, tem-se baixa especificidade do trabalho por não haver, praticamente, nenhum custo em treinamento. Porém, mesmo não tendo necessidade de investimento em capital humano, os custos de transação não estão eliminados. A firma incorre em custos ao manter transações com o mercado de trabalho; além disso, os custos de transação imputados pelas instituições jurídicas podem ser altíssimos quando o sistema de contratação é irregular. Neste contexto, o ambiente institucional pouco aparece nesses modelos e assume uma dimensão significativa para os trabalhadores pouco qualificados e com pequeno poder de barganha.

\subsection{O ambiente institucional e a contribuição da NEI}

O trabalho de Coase (1937) "The Nature of the Firm" apresenta a gênese da teoria dos contratos. Na formulação teórica do autor, os contratos emergem como instrumentos que expressam a estrutura legal que rege as instituições do sistema econômico. Portanto, as instituições do sistema econômico têm que se acomodar dentro do sistema judiciário vigente. Em trabalho mais recente, Coase (1988) aponta que os governos influenciam as ações dos agentes econômicos por meio da mudança das leis e/ou suas administrações ${ }^{6}$.

Incorporar à análise econômica o ambiente institucional é relevante, principalmente em se tratando das organizações, uma vez que o funcio-

\footnotetext{
${ }^{6}$ Stigler (1992) analisa a interação entre a economia e o direito.
} 
namento do sistema econômico recebe muita influência das instituições (RUTHERFORD, 1996).

Do ponto de vista da NEI, existe o reconhecimento de que a operação e a eficiência de um sistema econômico têm suas limitações e gargalos influenciados pelo conjunto de instituições que regulam o ambiente econômico (FARINA et al.,1997). Os mercados eficientes são conseqüência de um conjunto de instituições que fornecem, com baixo custo, as medidas e os meios para que os contratos sejam cumpridos, sendo o contrário também verdadeiro (OLIVEIRA, 1998). Como as instituições se comportam, como se relacionam e de que maneiras elas estão arranjadas na sociedade é o que caracteriza a eficiência, ou não, do sistema econômico. As instituições são, então, responsáveis pelo desempenho econômico das sociedades e de sua evolução (NORTH, 1994).

$\mathrm{O}$ ambiente institucional constitui o que alguns autores definem como as "regras do jogo". Estas promovem o desenvolvimento das atividades econômicas bem como as ações políticas, legais e sociais que governam a base da produção, troca e distribuição (WILLIAMSON, 1996). Os conjuntos de normas e regras delimitam as ações estabelecidas pelo homem, disciplinando suas ações com seus semelhantes e com o mundo, podendo também regulamentar outras instituições, definindo os critérios que serão estabelecidos por meio das duas formas de regras - formais e informais.

O ambiente institucional ganha importância quando os custos de transação não podem ser negligenciados. Não existindo nenhum sistema com esse custo nulo, as instituições devem ser analisadas e consideradas (NORTH, 1994). As instituições criam e delimitam o ambiente onde ocorrerá a transação e onde as organizações irão atuar.

Segundo Pinheiro (1996), o produto do sistema judiciário afeta a decisão dos agentes econômicos do ponto de vista da freqüência das ações litigiosas. O autor ainda destaca que o bom funcionamento do sistema judiciário não é devido ao seu uso; pelo contrário, tem o papel de estimular os agentes a realizarem transações, sendo resguardado para obrigar o cumprimento dos contratos e proteger o direito de propriedade. No universo do mercado de trabalho agrícola, será a efetividade das instituições jurídicas que forçará o enquadramento de empregado e empregador estarem de acordo com o sistema judiciário. Nas regiões onde estão menos presentes as instituições jurídicas (Delegacia do Trabalho, Ministério Público do 
Trabalho e Justiça do Trabalho), o sistema de contração adotado pelos empregadores tende a ser de menor custo e invariavelmente irregular.

Portanto, em razão da baixa qualificação e do reduzido poder de barganha do trabalhador temporário, as instituições jurídicas assumem um papel de grande funcionabilidade. Analisando-se o tratamento que é dado ao sistema de contratação do trabalho e o ponto de vista dos agentes das instituições jurídicas, é possível constatar as modalidades mais sujeitas a riscos de ordem institucional, gerando potenciais custos de transação para as empresas contratantes, quando realiza contratação de trabalhadores incompatível com o que delegam as instituições jurídicas.

No entanto, o mercado de trabalho no Brasil tende a se tornar mais flexível acompanhando a tendência internacional. Nesse sentido, o Congresso Nacional aprovou, em 5 de dezembro de 2001, a Lei n. 5.483/01, que modifica a 618 da CLT. Na nova Lei, as condições de trabalho, ajustadas mediante convenções e/ou negociações coletivas, devem prevalecer sobre o disposto em lei, desde que se respeitem a Constituição Federal e as normas de saúde e segurança do trabalho. Em outras palavras, buscase dar prevalência do "negociado sobre o legislado".

Dessa forma, o poder das instituições jurídicas é suprimido pelas decisões entre as partes contratantes, o que, de certa forma, beneficia o surgimento das cooperativas rurais, que funcionaria como um sindicato e que, portanto, teria mais poder de barganha.

Cabe ressaltar, conforme Vandeman (1992), que a função de um sistema de contratação de trabalho deve ser considerada em dois níveis: no mercado de trabalho e no processo de produção. A função do mercado de trabalho inclui o recrutamento e o assalariamento dos trabalhadores. No processo de trabalho, o objetivo é induzir a mão-de-obra ao processo produtivo com a finalidade de alcançar níveis ótimos de esforço e qualidade. No caso deste estudo, analisa-se apenas o mercado de trabalho agrícola, e, particularmente, o sistema de contratação dos trabalhadores agrícolas temporários, detalhando o caso das cooperativas de trabalhadores rurais.

\section{Sistema de Contratação}

O importante é diferenciar contrato agrícola e contrato de trabalho agrícola. Segundo Nahas (2001), os contratos agrários são basicamente 
os de parceria e de arrendamento, e são disciplinados pela legislação agrária. Esses contratos agrícolas propiciam esteio para formar propriedades agropecuárias de caráter temporário e rudimentar (IBGE, 1998). Como já indicado em seção anterior, os parceiros e os arrendatários são trabalhadores assalariados disfarçados, oriundos da herança do período colonial, visto que houve impedimentos ao acesso à propriedade da terra devido à conhecida Lei de Terra ${ }^{7}$. Portanto, para muitos indivíduos esses contratos agrícolas permitiam o trabalho na terra. Segundo Fonseca (2000), a parceria rural é largamente usada no Brasil ainda como uma herança social que encontrava bases legais no Código Civil de 1916. Para este autor, o parceiro trabalhador em nada se diferencia do empregado, arcando, contudo, com os riscos da atividade econômica e amargando a falta de proteção social. No entanto, essas formas contratuais agrícolas, que por muitas vezes delineiam relações entre empregado e empregador, são amplamente utilizadas pelas firmas rurais, encontrando poucas barreiras das instituições jurídicas. Conforme constata Fonseca (2000), as reclamações trabalhistas tendem ao insucesso em razão principalmente das dificuldades concernentes de obter provas. Os contratos de trabalho agrícola são atualmente regidos pela Lei promulgada em 1973 e, subsidiariamente, pela CLT, substituindo o antigo Estatuto da Terra.

A contratação da mão-de-obra pode ser feita por meio de recrutamento direto por parte dos produtores rurais ou por meio de intermediários, os quais são denominados de "gatos”. Estes são agenciadores de mão-deobra agrícola, aos quais também compete o transporte dos trabalhadores, coordenar a mão-de-obra do grupo de trabalhadores e prestar conta das atividades exercidas por esse grupo perante os tomadores desse serviço.

Segundo Fonseca (2000), são constantes as autuações desses intermediários pelo poder público devido às precariedades dos meios de transporte nos quais são conduzidos os trabalhadores, por acidentes rodoviários, por falta de concessão de equipamentos de proteção individual, por falta de condições sanitárias mínimas, e, além disso, é

\footnotetext{
${ }^{7}$ Lei de Terra promulgada em 1850 proibia o acesso à propriedade da terra a não ser por meio de compra. Sabendo-se que os indivíduos que dispunham de recursos financeiros naturalmente tinham grande influência no Governo Imperial, o que facilitava serem agraciados como proprietários de terra. Além disso, sem contar outras formas ilícitas de obter registro de propriedade.
} 
muito freqüente o trabalhador não ser pago. As firmas que se utilizam dos serviços dos intermediários acabam sendo responsabilizadas como conseqüência natural das autuações e constata-se, também, grande proliferação das Reclamações Trabalhistas, desta forma, colocando ambas as partes em extrema insegurança.

Nessa modalidade de contração, os trabalhadores ficam expostos a toda ordem de insegurança, o que fatalmente acarreta problemas na extração do trabalho da mão-de-obra no processo produtivo, desta forma, reduzindo a eficiência laboral e aumentando os custos de produção. A firma também fica exposta aos custos de transação quando ocorre autuação destes intermediários pelo poder público.

O recrutamento direto da mão-de-obra pelo produtor com a finalidade de atender as necessidades sazonais das atividades agropecuárias pode ser efetuado por meio de vários tipos de contratos, como é o caso dos contratos de safras. Segundo Fonseca (2000), o desvirtuamento desse tipo de contrato é bastante freqüente por causa de várias razões: excesso de formalismo inerente a contratos dessa natureza, alternâncias sucessivas de contratos ou tentando-se burlar o pagamento das verbas rescisórias. Conforme o autor, há um grande número de processos que tramitam na Justiça do Trabalho sobre este tema.

Os custos com a mão-de-obra são elevados e sobre estes incidem, além do próprio salário, os outros encargos sociais e tributários, bem como os outros custos da firma transacionar com o mercado de trabalho, mesmo em se tratando de mão-de-obra não-qualificada. Esta situação é propulsora de arranjos contratuais irregulares, com a finalidade de reduzir toda ordem de custos. O sistema de recrutamento de trabalhadores temporários é formado por vários arranjos contratuais, muitos dos quais podem ser questionados em âmbito institucional, o que pode acarretar problemas ao contratante. Santos (2001) relata as conseqüências econômicas na relação entre o trabalhador agrícola e o empregador. O autor cita o caso de uma reclamação trabalhista já tramitada e julgada no estado do Paraná, na qual a falta de capacidade de quitação da dívida trabalhista por parte do empregador levou a que sua propriedade fosse a leilão. Tal exemplo mostra uma solução drástica para o proprietário da firma, no entanto serve como um ponto de referência para os agentes econômicos.

Com a finalidade de reduzir a problemática descrita nesta seção, surgi- 
ram outras formas de recrutamento de mão-de-obra, como as cooperativas de trabalhadores rurais, tema que é discutido na próxima seção.

\section{As Cooperativas de Trabalhadores Rurais}

A Lei n. 5.764/71 instituiu o regime jurídico das sociedades cooperativas, proporcionando total liberdade de escolha do objeto das cooperativas através do artigo 50: "As sociedades cooperativas poderão adotar por objeto qualquer gênero de serviço, operação ou atividade, assegurando-se-lhes a obrigação do uso da expressão "cooperativa" em sua denominação". O artigo $4^{\circ}$ define as características das sociedades cooperativas e no $\S 1^{\circ}$ do artigo 10 prevêem-se modalidades diferentes das já consagradas e citas na Lei, as quais deverão ser apreciadas pelo órgão controlador.

Segundo Viana (1997), entende-se como cooperativas de serviço aquelas que se dedicam à prestação de serviços a terceiros, enquadrandose perfeitamente no conceito formulado por Diva Benevides Pinho: “as cooperativas de produção podem ser entendidas, em sentido amplo, como associações que se destinam a eliminar o patrão, suprimir o assalariado e dar ao trabalhador, agrícola ou industrial, a posse dos instrumentos de produção e o direito de disposição integral do produto de seu trabalho”. Por exemplo, pode-se citar as cooperativas de médicos, que eliminam a figura do patrão, despendendo esforços para adquirir o imóvel, as instalações, os equipamentos e todo o material necessário à prestação dos serviços de saúde. Com efeito, ocorre a substituição do regime assalariado por uma participação nos ganhos da sociedade. $\mathrm{O}$ autor frisa que nas cooperativas de serviço inexiste o trabalho subordinado, uma vez que o grupo de associados dirige o empreendimento. Portanto, na literatura, na ótica das instituições jurídicas, as cooperativas dessa natureza rezam, geralmente, pela normalidade jurídica, não sendo objeto de intenso debate ou polêmica sobre a relação entre cooperados e contratantes de seus serviços.

Segundo Carrion (1999), a instituição jurídica foi tomada de surpresa quando a Consolidação das Leis do Trabalho (CLT), em 1994, recebeu um novo artigo, o 422 (parágrafo único): “Qualquer que seja o ramo de atividade da sociedade cooperativa, não existe vínculo empregatício entre ela e seus associados, nem entre estes e os tomadores de serviços daquele”. Segundo Falcão (1997 apud CARRION, 1999, p. 168), “A norma de 1994 veio silenciosamente para o mundo jurídico laboral, aprovada com 
a participação inocente e talvez inadvertida de uma parte do Congresso Nacional que se deixou motivar pela alegada conveniência de proteger os assentados do Movimento dos Sem-Terra, MST”. Os assentados rurais do sul do país atuam no sentido de aprovar a introdução do artigo 422 na CLT para obter proteção dos riscos inerente às cooperativas de assentados. O trabalho dos assentados é organizado em cooperativas, recebendo cada cooperado de acordo com sua participação no trabalho coletivo; além disso, prestam serviços para os outros produtores rurais vizinhos. O referido artigo visa a inibir as tentativas de assentados que tenham saído das cooperativas, de pretender o reconhecimento de vínculo trabalhista entre eles e a cooperativa (VIANA, 1997).

Os indivíduos que participam das cooperativas de trabalho estão sujeitos a uma legislação própria, saindo da égide da CLT. Do ponto de vista do trabalhador, tem-se uma polêmica aberta sobre o quanto essa modalidade de trabalho retira aquilo que foi conquistado em termos de direito trabalhistas. Do ponto de vista do contratante, há grandes vantagens ao aderir a essa modalidade de contratação por meio da terceirização das etapas produtivas, pois reduz os custos referentes aos direitos trabalhistas. Segundo Pastore (1998), os encargos sociais impostos pela CLT são da ordem de $102 \%$, e de aproximadamente $40 \%$ quando se contratam os serviços de uma cooperativa de trabalho.

Figura 1 - Evolução do número de Cooperativas, dos principais ramos, registradas na OCB, 1990 a 2002.

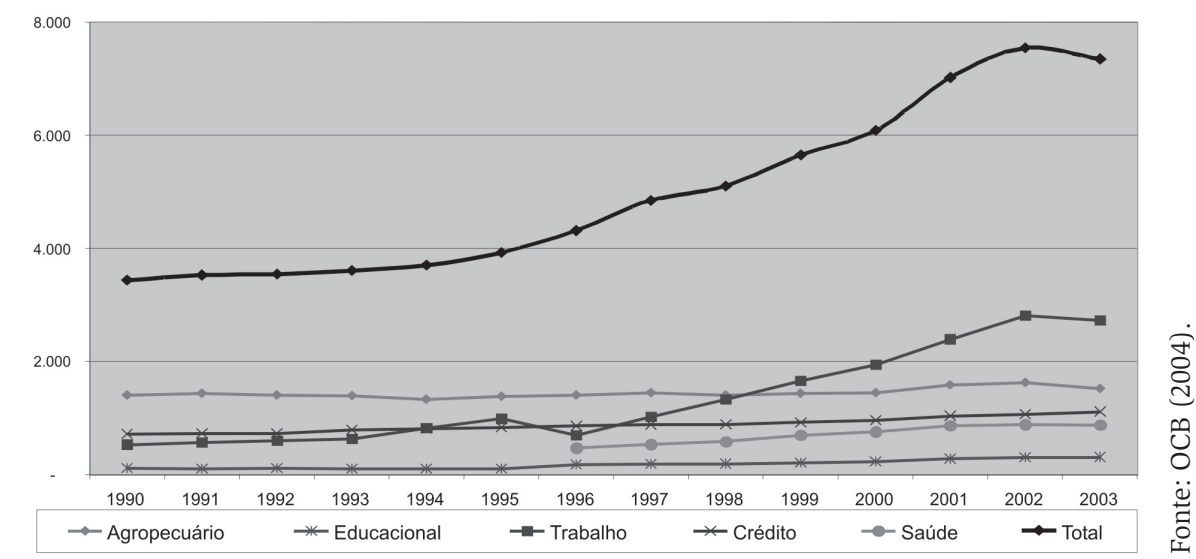

Obs.: 1.) de 1990 a 1995 as cooperativas médicas faziam parte do ramo de trabalho. A partir de 1996, elas foram excluídas daquele ramo.2.) Ano 2002 - As cooperativas de transporte estão inclusas no Ramo Trabalho, apesar de ter sido criado o Ramo Transporte em julho/2001. Fonte : Núcleo Banco de Dados - elaboração : GETEC/OCB 
Na Figura 1 fica expresso o vertiginoso crescimento das cooperativas de trabalho no Brasil tanto de trabalhadores que exercem atividades rurais como urbanas, no período de 1990 a 2001, a partir da segunda metade da década de 1990. O. Segundo Gimenez, Krein e Biavaschi (2003), apesar da precariedade dos dados sobre a expansão e proliferação das cooperativas de trabalho no Brasil, este movimento é bastante significativo. Evidências empíricas indicam essas cooperativas não estarem somente em setores menos dinâmicos da economia ou mesmo no setores em que concentra mão-de-obra menos especializada - setor agropecuário e vestuário -, mas se alastram em setores que oferecem postos de trabalho mais qualificado, como centro de processamento de dados, serviços de engenharia, e outros. Os autores ressaltam a importância dessas cooperativas e o seu mérito, mas deve-se considerar o seu papel no processo em curso de desestruturação das relações de emprego formais e no acesso aos direitos decorrentes do contrato de trabalho.

Cremonesi e Melo (2001) destacam a proliferação desenfreada da contratação de trabalhadores cooperados no meio rural e citam a colheita da laranja como o exemplo mais notório A produção de laranja do estado do São Paulo destinada à industrialização é oriunda de pomares da própria indústria e de produtores agrícolas de laranja - citricultores. Na década de 1980, período de grande expansão da cadeia citrícola, foi implantado o contrato-padrão, o qual atrelava o preço da caixa de laranja às cotações do suco no mercado internacional. Segundo Vieira (1988) apud Alves e Almeida (2000), as negociações para o estabelecimento de preços passaram a ser realizadas entre as associações de produtores e das indústrias, reduzindo os conflitos existentes. Em 1995, foi rompido o contrato-padrão devido a uma nova conjuntura no mercado internacional do suco de laranja, situação esta que depreciou os preços deste produto no mercado externo, e desencadeou uma série de ajustamentos na cadeia citrícola para evitar a perda de rentabilidade.

Nos anos 90, a redução de margem de rentabilidade foi transferida para os agentes de menor poder de barganha no interior da cadeia produtiva dos citrus, os produtores rurais. Segundo Alves e Almeida (2000), a criação de cooperativas de trabalhadores rurais foi intensificada pelas indústrias de suco de laranja na região de Ribeirão Preto e teve, inicialmente, uma boa acolhida junto aos produtores de laranja, especialmente 
pós-rompimento do contrato padrão. A criação das cooperativas de trabalhadores foi a adequada para a redução dos custos de produção, pelo fato de desonerar os produtores de parte dos custos trabalhistas. A prática de utilizar as cooperativas de trabalhadores rurais foi também utilizada pelas indústrias em seus pomares próprios, e segundo Alves e Almeida (1999), esse pomares se expandiram com uma estratégia para aumentar o poder de barganha frente aos citricultores.

A ação da instituição jurídica se manifestando contrária à atuação das cooperativas de trabalhadores rurais ocorreu em vários momentos, deste modo, o que inicia um processo de interpelação judicial entre os reclamados e dos reclamantes. Exemplo da atuação da instituição jurídica ocorre em 07 de novembro de 1996, quando Ministério Público do Trabalho e Ministério Público Federal da Procuradoria Regional do Trabalho da $15^{\circ}$ região e da Procuradoria da República em Ribeirão Preto entram com ação pública e liminar contra a indústria de suco de laranja Citrosuco Paulista S/A; Cooperativa de Trabalho dos Trabalhadores Rurais de São José do Rio Preto e Região - Cooper-Rio; e Cooperativa de Mão-de-Obra Rural - Coopmor. Os mesmos foram denunciados por meio do Ministério Público do Trabalho (MTP). No decorrer dos autos do acordão ${ }^{8}$ da $15^{\circ}$ Procuradoria Regional do Trabalho (PRT) de 1996. “Dois, portanto, são os elementos da fraude" (MINISTÉRIO PÚBLICO DO TRABALHO..., 1996):

a) total inexistência de autonomia no trabalho prestado pelos obreiros;

b) terceirização ilícita de atividade-fim das indústrias de suco.

Neste acordão é expresso várias vezes e de forma veemente a ilegalidade da contratação e funcionamento destas cooperativas de trabalhadores rurais (MINISTÉRIO PÚBLICO DO TRABALAHO..., 1996):

A partir da interpretação patronal dada à Lei 8.949/94, as citrícolas trataram de transformar suas empreiteiras em "cooperativas”, para o que arregimentaram os "gatos" que antes as serviam para montar o novo empreendimento. Daí os sugestivos apelidos de "coopergatos" e "gatooperativas" com que os participantes do III Congresso de Direito do Trabalho Rural, realizado pelo E. TRT da $150^{\text {a }}$ Região na cidade de Ribeirão Preto em 1995, brindaram o surgimento dessa nova forma de fraude à legislação trabalhista. 
No teor da denúncia são requeridos pelo órgão propositor (MINISTÉRIO PÚBLICO DO TRABALHO..., 1996):

1. Declaração da ilegalidade da prática de terceirização nas atividades-fins da primeira reclamada, relacionadas à colheita da laranja;

2. Condenação da primeira reclamada no sentido de se abster, definitivamente, da prática aludida, provendo esse tipo de mão-de-obra, que lhe é essencial, nos moldes previstos na CLT e na Lei $n^{\circ} 5.889 / 73$, com vinculação direta a seus quadros funcionais, em quaisquer de seus estabelecimentos ou filiais, assegurada toda a gama de direitos trabalhistas, sociais e os específicos da categoria profissional dos trabalhadores rurais do setor da citricultura;

3. Declaração de inidoneidade das cooperativas reclamadas para o fornecimento de mão- de- obra;

4. $\mathrm{Na}$ forma do art. 11 da Lei $\mathrm{n}^{0} 7.347 / 85$ ("astreintes”) c.c. art. 287 do C.P.C., não havendo cumprimento do preceito da sentença, ou seu retardamento, seja a primeira reclamada condenada ao pagamento de multa diária correspondente a 5.000 (cinco mil) UFIRs (ressalvada a alteração por outro indexador que a substitua), revertida em favor do FUNDO DE AMPARO AO TRABALHADOR (FAT), criado pela Lei $n^{\circ} 7.998 / 90$;

5. Em caráter sucessivo, apenas na remota hipótese de não se reconhecer como empregadora a indústria, que sejam declaradas como tais as cooperativas, por força do que dispõe o art. 41 da Lei $n^{\circ} 5.889 / 73$, declarando-se, outrossim, a responsabilidade solidária da prestadora e da tomadora;

Gimenez, Krein e Biavaschi (2003) analisaram uma ampla coleta de acordãos dos Tribunais Regionais do Trabalho da $4^{\mathrm{a}}$, 6a , $^{\mathrm{a}}$ e $15^{\mathrm{a}}$ Regiões para os períodos 1997 a 2001, e verificaram que a tendência dessas decisões era de coibir a fraude a direitos dos trabalhadores e de evitar ou inibir o processo atual de proliferação das cooperativas de trabalho "fraudulentas".

Além da atuação direta da instituição jurídica, foi produzida vasta literatura dentro desta ótica que analisa as cooperativas de trabalhador rural (VIANA, 1997; CARRION, 1999; FONSECA, 2000; CREMONESI; MELO, 2001), expressando a mesma opinião sobre a ação fraudulenta na maciça maioria dessas cooperativas. Conforme destaca Viana (1997, p. 1.476): “[...] não é lícito terceirizar empregados. Nossa ordem jurídica só 
autoriza a terceirização de serviços”. Ainda o mesmo autor conclui: “Se a empresa prestadora não tem atividade própria; se seu objetivo se limita ao fornecimento de mão-de-obra para a tomadora, não há terceirização, e sim, autêntica marchandage [...]. O mesmo ocorre com as cooperativas [...]. As mesmas regras que se aplicam a uma sociedade comercial, para terceirização, valem para as cooperativas” (VIANA, 1997, p. 1476).

Nas ações investigativas sobre a autenticidade das cooperativas de trabalho rural realizadas por instituições jurídicas, verificou-se que essas associações, em grande número, foram criadas pelos intermediários ("gatos") e, também, criadas pelas firmas contratantes, demitindo os seus empregados e incentivando a formação de cooperativas de trabalho para evitar os encargos trabalhistas.

Diante da posição do sistema judiciário e da atuação de suas instituições, as firmas contratantes dos serviços dessas cooperativas, mesmo imbuídas de legítimas intenções de terceirizar etapas da produção no período de safra, estão sujeitas a incorrer em altíssimos custos de transação. Esses custos incorrem em razão da proibição de continuar usando os serviços dos cooperados, interrompendo abruptamente a atividade ou, até mesmo, em razão de o Ministério do Trabalho caracterizar o vínculo com a empresa tomadora, aplicando-se as penalidades administrativas (VIANA, 1997; CREMONESI; MELO, 2001). Segundo Cremonesi e Melo (2001), não se pode admitir que o dispositivo legal que cria as cooperativas de trabalho resguarde a toda sorte de fraudes que são efetuadas pelas falsas cooperativas dessa natureza e tomadores de trabalhadores cooperados. O referido dispositivo legal perde efeito quando estiverem presentes os quatros requisitos da relação de emprego: habitualidade, pessoalidade, onerosidade e subordinação.

Nesta seção mostrou-se que a origem das cooperativas de trabalho teve o propósito lícito de prover as cooperativas de assentamentos; no entanto, passou a ser um instrumento de fraudes, incentivando um comportamento oportunista dos agentes econômicos. A firma contratante dos serviços dessas cooperativas, para suprir a sua rotina de produção, pode ter que suspender a contratação dos serviços de uma cooperativa de trabalho e procurar novos arranjos contratuais devido à atuação das instituições jurídicas. Portanto, há um custo de transação potencial nessa forma de contratação. 
Segundo Alves e Almeida (2000), apesar a atuação das instituições jurídicas, por meio da Procuradoria Regional do Trabalho, no período de 1997/98 e 1998/99 ocorreu o crescimento da utilização de cooperativas de trabalhadores rurais entre os pequenos e médios produtores de laranja na tarefa da colheita. No entanto, em 2004, no cadastro das cooperativas de trabalhos da Organização das Cooperativas do Estado de São Paulo (OCESP), há registro de apenas duas cooperativas de trabalhadores ligados à produção agropecuária, sendo que as cooperativas citadas na ação jurídica referida anteriormente ou mesmo na pesquisa de Alves e Almeida (2000) não estão registradas na OCESP. Isto reflete em grande medida que a atuação da instituição jurídica está moldando a organização produtiva e a relação do trabalho na agropecuária.

\section{Considerações Finais}

O sistema judiciário é um dos fatores que contribuíram para o surgimento do trabalho temporário, bem como as transformações ocorridas no processo de produção agropecuária, impulsionado pela "modernização da agricultura” nos anos 60. O conjunto desses novos trabalhadores que surgiram no bojo destas transformações forma um segmento dentro do mercado de trabalho agrícola. As atividades sazonais inerentes à agropecuária requerem um sistema de contratação que respeite essas características.

No caso específico das cooperativas de trabalho, diante da discussão apresentada, verifica-se que a atuação das instituições jurídicas introduz um componente potencial para limitar a contratação dos serviços de cooperativas de trabalho. Portanto, o segmento dos trabalhadores temporários está em completa transição em termos jurídicos, enquanto agentes econômicos formam um mercado fundamental para empresas rurais. Os custos de transação em recorrer ao mercado de trabalho fazem parte do processo de coordenação das atividades das empresas agrícolas. Os custos potenciais imputados pelas instituições jurídicas tendem a reduzir a utilização dessa modalidade de contratação, ocorrendo a migração para outras modalidades ou mesmo estimulando o surgimento de novos arranjos contratuais, como é o caso dos consórcios de empregadores rurais, que reduzem o comportamento oportunista. 
As regras jurídicas estabelecem ordenamento e sobrevida das relações trabalhistas em longo prazo, aceitando que elas são produto da vivência dos agentes econômicos envolvidos e das instituições. Os trabalhadores não-qualificados, os quais apresentam reduzido poder de barganha e baixíssima especificidade de capital humano, são fortemente dependentes da efetividade das instituições jurídicas para moldar o sistema de contratação do trabalho temporário agrícola.

\section{Referência bibliográficas}

ALVES, F.J.C.; ALMEIDA, L.M.C. Novas formas de contratação de mão-deobra rural na nova configuração do complexo agroindustrial citrícola paulista. Informações Econômicas, SP, v. 32, n.12, dez., p. 7-19. 2000.

ALVES, F.J.C.; ALMEIDA, L.M.C. Ascensão e queda das “gatoperativas” de mão-de-obra rural no complexo agroindustrial paulista. In: ENCONTRO NACIONAL DE ENGENHARIA DE 'PRODUÇÃO - ENEGEP, nov. 1999, Rio de Janeiro. Anais. Rio de Janeiro: ADREPO, 1999. Cd-rom.

AMADEO, E. J. Desemprego e evidências sobre a experiência recente na OECED (I). Revista Brasileira de Economia, v. 46, n. 2, p. 261-286, 1992.

AMADEO, E. J. Emprego no Brasil: diagnóstico e políticas. Brasília: MTb, 1999. 84 p.

AGUIRRE, B. M. B.; BIANCHI, A. M. Reflexões sobre a organização do mercado de trabalho agrícola. Revista de Economia e Política, v. 9, n. 1, p. 31-46, 1989.

BRANT, C. V. População e força de trabalho no desenvolvimento da agricultura brasileira. São Paulo: CEBRAP, 1977. 33 p.

CACCIAMALI, M. C. A legislação trabalhista no campo e sua aplicação entre os "bóias-frias" no estado de São Paulo: uma contribuição para o debate. In: DUARTE, D. (Org.). Emprego rural e migrações na América Latina. Recife: Massangana/Fundação Joaquim Nabuco, 1986. p. 51-64.

CACCIAMALI, M. C. Processo de informalidade, flexibilização das relações de trabalho e proteção social na América Latina: perdas na 
contribuição à seguridade social no Brasil. São Paulo: FEA/PROLAM-USP. Texto para Discussão, out. 2001. 34 p.

CARRION, V. Cooperativas de trabalho: autenticidade e falsidade. Revista LTr, v. 63, n. 2, p. 167-169, fev. 1999.

COASE, R. H. The nature o the firm. Econômica, n. 4, Nov. 1937.

COASE, R. H. The firm, the market and law. The University of Chicago Press, 1988.

CREMONESI, A.; MELO, O. Contratação fraudulenta de trabalhadores por intermédio de cooperativas de trabalho. Revista LTr, v. 65, n. 2, p. 176-179, fev. 2001.

FARINA, E. M. M. Q. Competitividade e coordenação de sistemas agroindustriais: um ensaio conceitual. Gestão \& Produção, São Carlos, v. 6, n. 3, p. 147-161, dez. 1999.

; AZEVEDO, P. F.; SAES, M. S. M. Competitividade: mercado, Estado e organizações. São Paulo: Singular, 1997. 286 p.

FONSECA, R. T. M. Consórcio de empregadores: uma alternativa imediata para a empregabilidade. Revista do Ministério Público do Trabalho, n. 20, XX, p. 79-89, set. 2000.

FREITAS, P. S. Oferta e demanda de mão-de-obra na determinação de diferencial de salários: uma análise para cinco gêneros manufatureiros na grande São Paulo. 1992. 139 p. Dissertação (Mestrado) - FEA, USP, São Paulo, 1992.

FROYEN, R. Macroeconomia. São Paulo: Saraiva, 1999. 635 p.

GIMENEZ, D.M.; KREIN, J.D.; BIAVASCHI, M.B. As cooperativas de mão-de-obra e os tribunais regionais do trabalho. Revista da ABET, n. 3, n. 1, 2003. (www.race.nuca.ie.ufrj.br/abet/revista/)

GOODMAN, D. E.; SORJ, B.; WILKINSON, J. Agroindústria, políticas públicas e estruturas sociais rurais: análise recente sobre a agricultura brasileira. Revista de Economia Política, v. 3, n. 4, p. 31-55, 1985.

INSTITUTO BRASILEIRO DE GEOGRAFIA E ESTATISTICA - IBGE. Censo Agropecuário do Brasil. Rio de Janeiro: FIBGE, 1988. 
INSTITUTO BRASILEIRO DE GEOGRAFIA E ESTATISTICA - IBGE. Pesquisa nacional por amostra de domicílio (PNAD) de 1997. Rio de Janeiro: FIBGE, 1999.

KEYNES, M. J. A teoria geral do emprego, do juro e da moeda. São Paulo: Nova Cultural, 1985, 352 p. (Os Economistas)

LIMA, R. Mercado de trabalho: o capital humano e a teoria da segmentação. Pesquisa e Planejamento Econômico, v. 10, n. 1, p. 217-272, 1980. MINISTÉRIO PÚBLICO DO TRABALHO...., 1996. Disponível no stie www. Prt15.gov.br_publicacao_coop.html. Acesso em 12 de agosto de 2004 . MELLO, D. M. C. “Bóia-fria”: acumulação e miséria. Petrópolis: Vozes, 1975. $154 \mathrm{p}$.

NAHAS, T.C. Inovações na Lei do Trabalhador Rural. Suplemento Trabalhista LTr, v. 37, 007/01, p. 35-38, 2001.

NORTH, D. Custos de transação, instituições e desempenho econômico. Rio de Janeiro: Instituto Liberal, 1994. 38 p.

OLIVEIRA, C. A. C. N. V. O surgimento das estruturas híbridas de governança na indústria de energia elétrica no Brasil: a abordagem institucional da economia dos custos de transação. 1998. 207 f. Dissertação (Mestrado) - Departamento de Ciências Econômicas, Universidade Federal de Santa Catarina, Florianópolis.

PASTORE, J. E. G. Cooperativismo coerente. Revista LTr, v. 62, n. 5, p. 639-641, maio 1998.

PASTORE, J. E. G. Cooperativas de trabalho: o fenômeno da terceirização. Revista LTr, v. 63, n. 10, p. 1.334-1.337, out. 1999.

PINHEIRO, A. C. Judicial system performance and economic development. Ensaios BNDES 2, Oct. 1996. 51 p.

REICH, M.; GORDON, D. M.; EDWARDS, R. C. A theory of labor market segmentation. The American Economic Review, v. LXIII, n. 2, p. 359365, 1973.

RUTHERFORD, M. Institutions and economics: the old and new institutionalism. Cambridge: Cambridge University Press, 1996. 225 p. 
SANTOS, F. O. Efeitos da prescrição dos direitos trabalhistas no meio rural paranaense. In: CONGRESSO BRASILEIRO DE ECONOMIA E SOCIOLOGIA RURAL, 39., SOBER, Recife, 2001. Anais... Recife, SOBER, 2001. p. 190.

SIDON, J. M. O. Dicionário jurídico: academia brasileira de letras jurídicas. Rio de Janeiro: Forense Universitária, 4ª edição, 1996.

STIGLER, G. J. Law or economic? The Journal of Law and Economics, v. 35, n. 2, p. 455-468, Oct. 1992.

VANDERMAN, A.; SADOULET, E.; JANVRY, A. Labor contracting and a theory of contract choice in California agriculture. American Journal of Agricultural Economics, v. 73, n. 3, p. 681-692, Aug. 1991.

VIANA, M. J. M. Cooperativas de trabalho: terceirização de empregados ou terceirização de serviços? Revista LTr, v. 61, n. 11, p. 1.473-1.478, nov. 1997.

VIEIRA, A.C. O complexo agroindustrial citrícola nos anos 90: novos fatores na relação agricultura/indústria e desafios para o segmento de produção agrícola. São Carlos:UFSCar, 1988. (dissertação de mestrado) WILLIAMSON, O. E. The economic insitutions of capitalism. New York: Free Press, 1985.

. The mechanism of governance. New York: Oxford University Press, 1996. 429 p. 